\title{
Depressive Symptoms and Health-Related Quality of Life in Breast Cancer Survivors
}

\author{
Cielito C. Reyes-Gibby, Dr.P.H., ${ }^{1}$ Karen O. Anderson, Ph.D., ${ }^{2}$ Phuong Kanh Morrow, M.D., ${ }^{3}$ \\ Sanjay Shete, Ph.D., and Sohela Hassan, Ph.D.
}

\section{Abstract}

Background: Breast cancer diagnosis and treatment can have a profound influence on a woman's physical, psychosocial, and overall well-being. We examined the prevalence of depressive symptoms and its association with health-related quality of life (HRQOL) in women who are survivors of breast cancer. We also assessed if factors, including metastasis, cancer recurrence, diagnosis of new primary cancers, and comorbid conditions, are associated with depressive symptoms.

Methods: The Patient Health Questionnaire (PHQ-8) and European Organization for Research and Treatment of Cancer Quality of Life Questionnaire Core 30 were mailed to assess depressive symptoms and HRQOL, respectively, in breast cancer patients who received cancer treatment in a large tertiary cancer center.

Results: Two hundred forty patients participated (56\% response rate and 6-13 years since treatment). The mean score on the PHQ-8 scale was 4 points (standard deviation [SD] 4.8, median 2.0). Sixteen percent had PHQ-8 score $\geq 10$ and were categorized as depressed. Depression was inversely associated with HRQOL subscales for functioning, financial, and global health and positively associated with symptoms. Logistic regression showed that younger age (odds ratio [OR] age in years $0.92,95 \%$ confidence interval [CI] 0.86- 0.99, $p<0.02$ ), rheumatoid arthritis (OR 8.4, 95\%CI 1.3-57.4, $p<0.03$ ), and years from treatment (OR 0.70, 95\% CI 0.46-0.99, $p<0.05$ ) were significant correlates of depression.

Conclusions: Depression is a significant health concern for breast cancer survivors and is associated with lower HRQOL. The results suggest the need to monitor women with breast cancer for depression and provide resources for treating depression during the survival period.

\section{Introduction}

B REAST CANCER IS THE MOST PREVALENT CANCER in WOmen and a significant cause of mortality and morbidity in the United States, with an estimated 209,060 new cases of invasive breast cancer in 2010 alone. $^{1}$ Advances in breast cancer treatment have markedly prolonged survival time. To date, there are more than 2 million breast cancer survivors in the United States. ${ }^{2}$ Breast cancer diagnosis and treatment can have a profound influence on a woman's physical, psychosocial, and spiritual well-being, compromising their quality of life. ${ }^{3,4}$ Depression, in particular, has a strong and complex relationship with cancer. ${ }^{3}$ Depression has been associated with disease severity, ${ }^{5}$ level of patient disability, ${ }^{6}$ physical impairment, ${ }^{7,8}$ poor performance status ${ }^{9-11}$ and survival. ${ }^{12}$ It is also known that depression is a major source of distress and can have a profound impact on the quality of life (QOL) of breast cancer survivors. ${ }^{13-16}$ Given the anticipated increase in the number of breast cancer survivors over the next few decades, understanding the epidemiology of depression and its adverse impact on QOL during the survival period has high clinical and public health significance.

Studies show the significant impact of depression and depressive symptoms well beyond the treatment phase of cancer. Burgess et al. ${ }^{17}$ observed that of 170 women with early stage breast cancer, nearly 50\% had depressive symptoms and anxiety in the year after diagnosis, $25 \%$ in the second, third, and fourth years, and $15 \%$ in the fifth year. Den Oudsten et al. ${ }^{18}$ found that before diagnosis, $40.9 \%$ of the women reported depressive symptoms, and as many as $27.8 \%$ reported symptoms 1 year later. Vahdaninia et al. ${ }^{19}$ likewise observed improvement of depression at 18 months follow-up $(p<0.001)$, although as many as $22.2 \%$ of the breast cancer patients reported depression during the same follow-up

${ }^{1}$ Department of Epidemiology, Division of Cancer Prevention and Population Sciences, ${ }^{2}$ Symptom Research, Division of Internal Medicine, and ${ }^{3}$ Breast Medical Oncology, Division of Cancer Medicine, The University of Texas M.D. Anderson Cancer Center, Houston, Texas. 
period. As further evidence to support this trend, Kim et al. ${ }^{20}$ found that of 1933 breast cancer survivors who had undergone primary curative surgery for breast cancer between 1993 and 2002, 24.9\% reported depression. When stratified by years since surgery, $14.5 \%$ and $8.7 \%$ of those who had curative surgery $<5$ years and $\geq 5$ years ago, respectively, reported depression. Thus, time since treatment or diagnosis has consistently been associated with prevalence of depression in studies of breast cancer survivors.

Very few studies, however, have investigated factors that might be associated with depression in breast cancer survivors. In this study, we surveyed breast cancer survivors who received cancer chemotherapy between the years 1994 and 2001 in a large tertiary cancer center. Using the Patient Health Questionnaire (PHQ-8), we assessed the prevalence of depressive symptoms and the extent of their association with QOL in this sample. We also assessed if factors, including metastasis, cancer recurrence, occurrence of other primary cancers, and comorbid conditions, are associated with depression. The long-term goal is to provide information that will help direct intervention efforts for depression to ensure a better QOL for breast cancer survivors.

\section{Materials and Methods}

In this cross-sectional study, we surveyed breast cancer survivors who participated in clinical trials of paclitaxel between 1994 and 2001 at The University of Texas MD Anderson Cancer Center (Houston, TX). ${ }^{21,22}$ We searched institutional databases and identified 635 breast cancer patients, 430 of whom were alive, are residents of Texas, and had current contact information on file as of July 2007. MD Anderson typically sees > 2000 newly diagnosed breast cancer patients annually. For example, during the fiscal year September 2007September 2008, there were 2162 new female patients with breast cancer admitted at MD Anderson. Of these 2162 patients, 1487 resided in Texas at the time of registration. Of these Texas residents, 682 received chemotherapy at MD Anderson. Review of institutional databases suggests that $80 \%$ of these patients received paclitaxel therapy.

Patients were initially contacted by telephone up to three times. After we obtained verbal consent, patients were given a detailed explanation of the study. Questionnaires were subsequently sent to the patients' residences up to three times. Informed consent forms included in the questionnaire packet were signed by participants in accordance with procedures approved by the M.D. Anderson Cancer Center Institutional Review Board. Two hundred forty patients consented to participate (56\% response rate) in our study.

\section{Instruments}

To assess the prevalence of depression and its severity among the study participants, we used the standardized and validated, 8-item Patient Health Questionnaire (PHQ-8), which measures depressive symptoms as described in the DSM-IV on a 4-point $(0-3)$ scale. The questions were tallied to produce a total score of 0-24 points. ${ }^{23}$ A PHQ-8 score $\geq 10$ has a sensitivity of $88 \%$ and a specificity of $88 \%$ for a diagnosis of major depression and typically represents clinically significant depression. ${ }^{23-25}$ We used this scoring scheme to dichotomize our participating breast cancer survivors into two groups, those without depression ( $<10$ points) and those with depression ( $\geq 10$ points).
Health-related QOL (HRQOL) after treatment for breast cancer was assessed with the English-language version of the European Organization for Research and Treatment of Cancer Quality of Life Questionnaire Core 30 (EORTC QLQ-C30), version 3, a 30-question instrument designed specifically to assess HRQOL in patients participating in oncologic studies that has been tested in EORTC field studies. ${ }^{26}$ The EORTC QLQ-C30 is composed of 28 questions about functionality (physical, role, emotional, cognitive, and social), symptoms (fatigue, pain, nausea, vomiting, dyspnea, insomnia, appetite loss, constipation, and diarrhea), and financial difficulties owing to disease or treatment that patients rate on a scale of 1 (not at all) to 4 (very much) points. The last 2 questions concern global health status and are rated on a scale of 1 (very poor) to 7 (excellent) points. On the EORTC QLQ-C30, high scores on functional scales and for global health status represent high functionality and good health, but high scores on the symptom scales represent high levels of symptom severity.

To better characterize our study population, the questionnaire also included items assessing sociodemographic characteristics, disease-related factors, and comorbid conditions. Sociodemographic variables, including age, marital status, and educational level, were assessed. We also assessed disease-related factors, such as comorbidity, metastasis, recurrence, and the occurrence of other primary cancers, among these patients. History of comorbid conditions was assessed by asking patients if they had ever received a diagnosis of heart disease, stroke, hypertension, osteoarthritis, rheumatoid arthritis, lung disease, or diabetes. In addition, our previous studies have shown that these variables are significant correlates of health outcomes. ${ }^{21,22,27,28}$

\section{Statistical analyses}

Descriptive statistics were used to summarize patient characteristics. We assessed the normality distribution of selected variables using a one-sample Kolmogorov-Smirnov test. Nonparametric (Mann Whitney U test and KruskallWallis analyses of variance [ANOVA]) measures of correlation were conducted to test the association of depressive symptoms with QOL subscales. We calculated the variable time since treatment as time difference between the date of initiation of paclitaxel therapy and the date when patients responded to the survey.

Similar to previous studies, the prevalence of depression was assessed using the PHQ cutoff of $\geq 10 .^{7,23}$ We conducted multivariable logistic regression analysis to assess the factors associated with depression. Candidate variables included comorbidities (hypertension, heart disease, lung disease, rheumatoid arthritis, osteoarthritis, diabetes, stroke), posttreatment disease-related factors (metastasis, recurrence, and diagnosis of new primary cancer), sociodemographic characteristics (age, educational level, marital status), and years since treatment. In the multivariable analysis, the first model included all variables considered significant $(p<0.20)$ in the univariate analysis. A $p$ value of 0.20 was used as the cutoff because a more traditional value (e.g., $p<0.05)$ often does not identify variables known to be important. ${ }^{29}$ Further variable selection in the model was conducted using backward elimination. To obtain the most parsimonious model, only variables with $p$ values $<0.05$ were included in the final model. All tests were two-sided. SPSS version 17 was used in the analyses. 


\section{Results}

\section{Study sample}

Two hundred forty breast cancer survivors participated in this survey (Table 1), achieving a 56\% response rate. The mean age was 58 years (standard deviation [SD] 16). Ninety-seven percent of the participants were white. Seventy-five percent of the women were married, and a majority completed a highschool education. Nine percent of the sample had local recurrence, and $8 \%$ had progressed to metastatic disease. The most common comorbid conditions were hypertension $(34 \%)$ osteoarthritis (30\%), diabetes $(10 \%)$, and rheumatoid arthritis $(6 \%)$. The years since treatment were between 6 and 13 years (mean 7.9, median 8).

\section{Prevalence of depressive symptoms}

The mean score on the PHQ-8 scale was 4 points (range 0-24, SD 4.8, median 2.0). The Kolmogorov-Smirnov $Z$ test showed that the PHQ-8 was not normally distributed $(p<0.001)$. Using a cutoff point of PHQ-8 score $\geq 10$ points, as many as $16.2 \%$ of breast cancer survivors can be categorized as being depressed. Figure 1 shows the prevalence of depression stratified by years since treatment. We observed a general decreasing trend in the prevalence of depression by years since treatment.

\section{Depression and Health-Related Quality of Life:}

The Kolmogorov-Smirnov Z test showed the EORTC QLQC30 score was not normally distributed $(p<0.001)$. We, therefore, assessed the association of high PHQ scores with EORTC QLQ-C30 subscales using the nonparametric Mann Whitney U test. As shown in Table 2, women who had PHQ$8 \geq 10$ and, therefore, were categorized as depressed scored significantly lower on items that measure cognitive (34 vs. 95), emotional (30 vs. 95$)$, role (48 vs. 92 ), physical (39 vs. 95), and social (50 vs. 93) functioning than women with $\mathrm{PHQ}<10$ scores (all $p<0.001$ ). Table 3 shows that except for constipation, women who were categorized as depressed also reported higher levels of fatigue (115 vs. 80), pain (140 vs. 80), insomnia (135 vs. 80$)$, appetite loss (103 vs. 84), diarrhea (115 vs. 84$)$, and dyspnea (119 vs. 82$)($ all $p<0.001)$ than women with low PHQ scores.

Table 4 shows that women who scored $\geq 10$ on the PHQ-8 reported higher financial burden scores (121 vs. 82), and in regard to global health, women who scored $\geq 10$ on the PHQ8 reported significantly $(p<0.001)$ lower global health scores (37 vs. 91) than women with low PHQ scores (PHQ-8<10).

\section{Correlates of depression}

Multivariable logistic regression analysis showed that of the candidate variables assessed, including disease-related factors (i.e., metastasis, cancer recurrence, diagnosis of new primary cancer, years since treatment), comorbidities (hypertension, heart disease, lung disease, rheumatoid arthritis, osteoarthritis, diabetes, stroke), and sociodemographic factors (age, educational level, marital status), only younger age (odds ratio [OR] age in years $0.92,95 \%$ confidence interval [CI] 0.86- 0.99, $p<0.02$ ), rheumatoid arthritis (OR 8.4, 95\% CI 1.3-57.4, $p<0.03$ ), and years from treatment (OR 0.70,95\% CI 0.46-0.99, $p<0.05$ ) were significant correlates of depression (Table 5).
Table 1. Characteristics of Study POPUlation $(n=240)$

\begin{tabular}{|c|c|}
\hline Mean age & $58(S D 16)$ \\
\hline \multicolumn{2}{|l|}{ Race/ethnicity } \\
\hline Non-Hispanic white & $233(97)$ \\
\hline Other & $7(3)$ \\
\hline \multicolumn{2}{|l|}{ Marital status } \\
\hline Married & $172(75)$ \\
\hline Divorced & $28(12)$ \\
\hline Widowed & $19(8)$ \\
\hline Separated & $1(0.4)$ \\
\hline Never been married & $9(4)$ \\
\hline Living with someone as couple & $2(1)$ \\
\hline \multicolumn{2}{|l|}{ Education } \\
\hline Less than high school & $2(1)$ \\
\hline Grade 12 , GED, or high school graduate & $43(18)$ \\
\hline Some college & $61(26)$ \\
\hline $\begin{array}{l}\text { College graduate, associate or bachelor's } \\
\text { degree }\end{array}$ & $71(31)$ \\
\hline $\begin{array}{l}\text { More than college (master or doctoral } \\
\text { degree) }\end{array}$ & $55(24)$ \\
\hline \multicolumn{2}{|l|}{ Employment status } \\
\hline Employed full-time & $80(35)$ \\
\hline Employed part-time & $21(9)$ \\
\hline Not employed & $45(20)$ \\
\hline Retired & $80(35)$ \\
\hline \multicolumn{2}{|l|}{ Stage of disease ${ }^{a}$} \\
\hline 0 & $46(20)$ \\
\hline I & $62(26)$ \\
\hline IIA & $82(34)$ \\
\hline IIB & $37(15)$ \\
\hline \multirow{2}{*}{\multicolumn{2}{|c|}{$\begin{array}{l}\text { IIIA } \\
\text { Surgery }\end{array}$}} \\
\hline & \\
\hline Modified radical mastectomy & $101(51)$ \\
\hline $\begin{array}{l}\text { Segmental with axillary lymph node } \\
\text { dissection }\end{array}$ & $53(27)$ \\
\hline Segmental sentinel biopsy & $28(14)$ \\
\hline Total mastectomy & $11(6)$ \\
\hline \multicolumn{2}{|l|}{ Radiotherapy $^{\mathrm{a}}$} \\
\hline Yes & $119(60)$ \\
\hline No & $79(40)$ \\
\hline \multicolumn{2}{|l|}{ Mestastasis } \\
\hline Yes & $14(6)$ \\
\hline No & $208(93)$ \\
\hline \multicolumn{2}{|l|}{ Recurrence } \\
\hline Yes & $21(9)$ \\
\hline No & $202(91)$ \\
\hline \multicolumn{2}{|l|}{ New primary } \\
\hline Yes & $20(9)$ \\
\hline No & $201(91)$ \\
\hline \multicolumn{2}{|l|}{ Comorbid conditions ${ }^{\mathrm{b}}$} \\
\hline Hypertension & $75(34)$ \\
\hline Osteoarthritis & $64(30)$ \\
\hline Diabetes & $21(10)$ \\
\hline Rheumatoid arthritis & $13(6)$ \\
\hline \multicolumn{2}{|l|}{ Years since treatment (paclitaxel) } \\
\hline Mean & 7.9 \\
\hline Median & 8 \\
\hline
\end{tabular}

a Abstracted from medical records.

${ }^{\mathrm{b}}$ Most commonly reported comorbidities.

GED, general equivalency diploma; SD, standard deviation. 
FIG. 1. Prevalence of depression (Patient Health Questionnaire, PHQ-8) by years since cancer treatment.

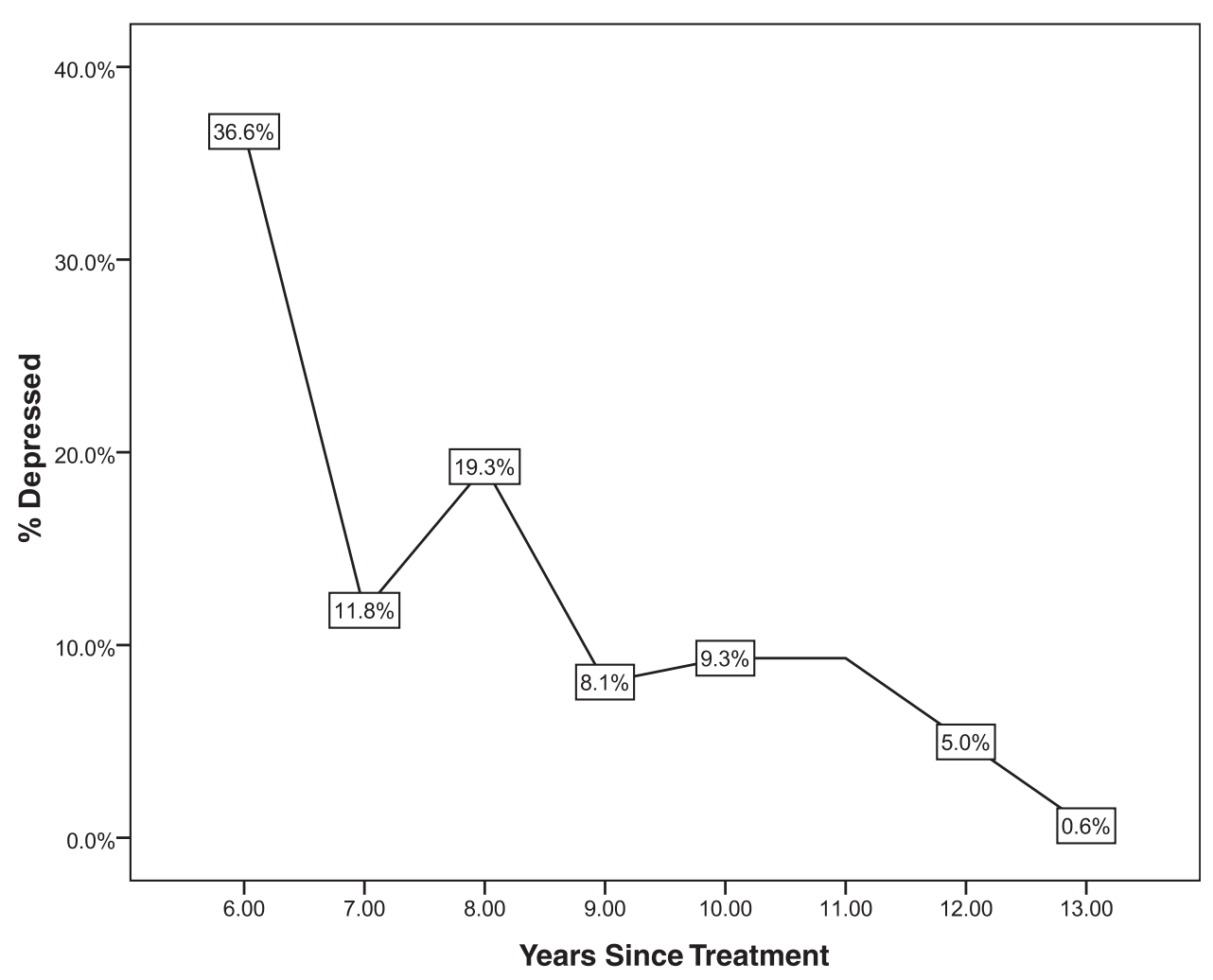

\section{Discussion}

This study examined the prevalence of depressive symptoms in 240 breast cancer survivors and found that $16 \%$ of women scored as depressed on the PHQ-8 6-13 years after treatment. This is consistent with other studies showing that the prevalence of depression in patients with cancer is estimated to be $15 \%-30 \%$ or higher. ${ }^{30,31}$ It should be noted, however, that a population-based survey in the United States of 198,678 of the general adult population showed that the prevalence of depression was around 9\% (PHQ-8 $\geq 10){ }^{23}$ lower than the prevalence in our study population. Among the implications of our study is the need to monitor depressive symptoms among breast cancer patients.

Table 2. Depression and Health-Related Quality of Life Functioning Subscale

\begin{tabular}{lccc}
\hline & \multicolumn{3}{c}{ Functioning subscales $^{\mathrm{a}}$} \\
\cline { 2 - 3 } & \multicolumn{3}{c}{ Mean rank } \\
\cline { 2 - 3 } & $\begin{array}{c}\text { With } \\
\text { depression }\end{array}$ & $\begin{array}{c}\text { Without } \\
\text { depression }\end{array}$ & \\
EORTC subscales & $($ PHQ-8 $\geq 10)$ & $($ PHQ-8<10) & $\mathrm{p}$ value \\
\hline Cognitive functioning & 34 & 95 & 0.0001 \\
Emotional functioning & 30 & 95 & 0.001 \\
Role functioning & 48 & 92 & 0.001 \\
Physical functioning & 39 & 95 & 0.001 \\
Social functioning & 50 & 93 & 0.0001 \\
\hline
\end{tabular}

${ }^{\text {a}}$ High scores on functional scales represent high functionality and good health.

${ }^{\mathrm{b}}$ Mann-Whitney U test.

EORTC, European Organization for Research and Treatment of Cancer; PHQ-8, Patient Health Questionnaire.
Consistent with previous studies, ${ }^{32-35}$ we also found that the prevalence of depression decreased with increasing time since treatment. The higher incidence of depression shortly after diagnosis and during treatment may be related to fears of death and recurrence, as well as side effects and impairments associated with treatment. The diagnosis and treatment of breast cancer typically disrupt a woman's life in multiple areas, including family, occupation, and physical function.

We found, consistent with other studies, that depression was significantly associated with QOL. ${ }^{36}$ Depressed women

Table 3. Health-Related Quality of Life and Depression: Symptoms Subscale

\begin{tabular}{lccc}
\hline & \multicolumn{3}{c}{ Symptoms $^{\mathrm{a}}$} \\
\cline { 2 - 3 } & \multicolumn{3}{c}{ Mean rank } \\
\cline { 2 - 3 } & $\begin{array}{c}\text { With } \\
\text { depression } \\
\text { EORTC subscales }\end{array}$ & $\begin{array}{c}\text { Without } \\
\text { depression }\end{array}$ \\
\hline Constipation & 86 & 87 & $\mathrm{NS}$ \\
Diarrhea & 115 & 84 & 0.001 \\
Fatigue & 115 & 80 & 0.0001 \\
Nausea and vomiting & 103 & 85 & 0.002 \\
Pain & 140 & 80 & 0.0001 \\
Dyspnea & 119 & 82 & 0.0001 \\
Insomnia & 135 & 80 & 0.0001 \\
Loss of appetite & 103 & 84 & 0.0001 \\
\hline
\end{tabular}

${ }^{\text {a}}$ High scores on the symptom scales represent high levels of symptom severity.

${ }^{\mathrm{b}}$ Mann-whitney U test.

NS, not significant. 
Table 4. Health-Related Quality of Life and

Depression: Global Health and Financial Difficulties Subscales

\begin{tabular}{|c|c|c|c|}
\hline \multirow[b]{3}{*}{ EORTC subscales } & \multicolumn{3}{|c|}{ Global health and financial difficulties ${ }^{\mathrm{a}}$} \\
\hline & \multicolumn{2}{|c|}{ Mean Rank } & \multirow[b]{2}{*}{$\mathrm{p}$ value } \\
\hline & $\begin{array}{c}\text { With } \\
\text { depression } \\
(P H Q-8 \geq 10)\end{array}$ & $\begin{array}{c}\text { Without } \\
\text { depression } \\
(P H Q-8<10)\end{array}$ & \\
\hline Financial difficulties & 121 & 82 & 0.001 \\
\hline Global health & 37 & 91 & 0.0001 \\
\hline
\end{tabular}

${ }^{a}$ High score on global health represent-good health, and high score on financial difficulties represents high level of financial difficulty.

had lower scores on all the functional subscales, and even after adjusting for other variables, these relationships persisted. Poorly managed depression is a major source of distress and impaired physical and social functioning for patients and families. ${ }^{37}$ Depression can also bring about postponement or cessation of therapies. Among the implications of our findings is the need to monitor patients for depressed mood and provide resources for treatment of depression within the clinical oncology setting to ensure a better QOL of breast cancer survivors. Short screening measures, such as the PHQ8 , are effective in identifying patients who are experiencing symptoms of depression and require further evaluation. Several studies of patients with cancer found that brief selfreport scales assessing depressive symptoms performed well when compared with more comprehensive depression scales or interviews. ${ }^{38-41}$ In addition, the National Comprehensive Cancer Network (NCCN) has developed a simple 1-item screening tool for emotional distress in individuals with cancer. ${ }^{42}$ The NCCN guidelines include an algorithm for further evaluation, diagnosis of depression, and appropriate interventions. Further research is needed to determine the most effective strategy for screening breast cancer survivors for depressive symptoms.

We found that women who were depressed had significantly higher financial burden scores, as measured by the EORTC QLQ-30. Depression has a high economic burden, not just for the individual but for society. ${ }^{43}$ At a societal level, it is estimated that in terms of the average cost per patient, de-

Table 5. Multivariable Model for Depression

\begin{tabular}{lccc}
\hline Variable $^{\mathrm{a}}$ & $\begin{array}{c}\text { Odds } \\
\text { ratio }\end{array}$ & $\begin{array}{c}\text { 95\% confidence } \\
\text { interval }\end{array}$ & $\begin{array}{c}\mathrm{p} \\
\text { value }\end{array}$ \\
\hline $\begin{array}{l}\text { Age (1 year interval) } \\
\text { Rheumatoid arthritis }\end{array}$ & 0.92 & $0.86-0.99$ & 0.02 \\
$\quad$ No & 1.0 & & \\
$\quad$ Yes & 8.40 & $1.30-57.4$ & 0.03 \\
$\begin{array}{l}\text { Years since treatment } \\
\text { (1 year interval) }\end{array}$ & 0.70 & $0.46-0.99$ & 0.05 \\
& & &
\end{tabular}

PHQ-8 $\geq 10$.

${ }^{a}$ Candidate variables included disease-related (i.e., metastasis, cancer recurrence, diagnosis of new primary cancer, years since treatment), comorbidities (hypertension, heart disease, lung disease, rheumatoid arthritis, osteoarthritis, diabetes, stroke), and sociodemographic factors (age, educational level, marital status). pression imposes a societal burden that is larger than that of other chronic conditions, such as hypertension, rheumatoid arthritis, asthma, and osteoporosis. ${ }^{43,44}$

Not surprisingly, we found that such symptoms as pain, insomnia, and fatigue were significantly associated with depression. Similar associations between symptoms and depression have been found in other samples of breast cancer survivors. Fatigue and pain were significantly associated with depression at 18 months posttreatment in a sample of 99 women. ${ }^{19}$ Other studies of breast cancer survivors have found strong associations between the self-report of pain or fatigue and emotional distress. ${ }^{35,45,46}$ Among the implications of these findings is the complexity of the management of depression, given the other symptoms attendant to its occurrence. Randomized clinical trials of breast cancer survivors who report depressed mood and other symptoms, such as fatigue, pain, and sleep disturbance, are needed to evaluate the relative efficacy of symptom management interventions and treatments that focus on depression.

We also found that younger age was a significant risk factor for depression in this sample. Previous studies of breast cancer survivors found that younger women were at greater risk for psychosocial distress than older women. ${ }^{17,47}$ Given that most cases of breast cancer occur in women $>50$ years of age, younger women who are diagnosed with breast cancer may be especially alarmed to receive a life-threatening diagnosis. ${ }^{48}$ These young women often have young children to care for during their cancer treatments and have to cope with the accompanying disruptions of family life. ${ }^{49}$ Younger women may have special concerns about the possibility of infertility and premature menopause as a result of cancer treatments ${ }^{50}$ and also are less likely than older women to have experience dealing with chronic illness and the healthcare system. Such factors may contribute to the greater risk of depression in younger women who are coping with the multiple stresses associated with breast cancer. ${ }^{51}$ Additional research is needed to develop effective interventions for younger breast cancer survivors who experience depression. Psychosocial interventions that might prevent the development of clinical depression in younger survivors also should be investigated.

We found that a self-reported diagnosis of rheumatoid arthritis was associated with depressive symptoms. Comorbidities, such as arthritis and impaired functional status, have been associated with emotional distress in other studies of breast cancer survivors. As rheumatoid arthritis is an independent risk factor for depression, ${ }^{52}$ it is not surprising that women who have this chronic illness as well as breast cancer are at increased risk of depression. Pain and fatigue are common symptoms of arthritis and have been identified as predictors of self-reported depression in patients with rheumatoid arthritis. ${ }^{53}$ It is not clear why the other comorbidities assessed in the present study were not significant risk factors for depression. It is possible that the small numbers of women with the individual comorbidities limited the statistical power to detect possible associations with depression.

Previous research has found an increased incidence of emotional distress associated with disease recurrence in women with breast cancer, ${ }^{17,54}$ but we did not find that disease recurrence was a significant risk factor for depression. However, we only had a small sample, thus possibly limiting our ability to detect the potential influence of these variables on depression in our sample. 
The breast cancer survivors who participated in our study were primarily married, educated, working, white nonHispanic women, and because this is a single-center study, the results are not generalizable. Furthermore, we did not have a large sample and, thus, may have had a low power to detect associations between depression and other disease-related variables. Importantly, because of the cross-sectional study design, we cannot assume causality in the observed relationship between the factors assessed and depression. For example, Schroevers et al. ${ }^{55}$ conducted a study of the long-term impact of a diagnosis of cancer and found that relative to a randomly selected sample of individuals without cancer, 8-year cancer survivors do not differ significantly in the level of depressive symptoms, anxiety, life satisfaction, self-esteem, social support, and marital satisfaction. However, survivors reported more physical symptoms, and those with a recurrence of cancer also reported more limitations in household and social activities. It has been shown that decreasing depression symptoms were associated with longer subsequent survival for women with metastatic breast cancer ${ }^{56}$ and that depression is a prognostic factor for breast cancer mortality. ${ }^{57}$ Additional studies with prospective designs and longer follow-up periods are needed to gain a better understanding of the causal relationships between the variables assessed in this study.

Our study had additional limitations. Although others may argue that PHQ-8 is not a reliable measure of depression compared to standardized psychiatric interviews, it should be noted that several large studies have confirmed the validity of the PHQ-8 as both a diagnostic and severity measure in clinical populations, ${ }^{24,58,59}$ and a large, population-based survey also showed that PHQ is a valid measure of depression. ${ }^{23}$ We also did not ask if our respondents were receiving treatment of depression. Similar to our findings, decreased levels of depression over time were found in a longitudinal study of breast cancer survivors that used a structured psychiatric interview with standardized diagnostic criteria. ${ }^{17}$ As information on chronic diseases was based on self-report, misclassification (grouping those with active vs. past/treated diseases) is a distinct possibility. In addition, information on metastasis, recurrence, and other primaries assessed were based on self-report, and recall bias is an important concern and may have led to a bias in the findings. Another limitation in the present study was the use of a mailed questionnaire. Although the response rate was a respectable $56 \%$, it is possible that response bias influenced the results. Unfortunately, we were not able to compare the characteristics of responders and nonresponders.

In conclusion, as breast cancer therapies continue to advance, a substantial number of breast cancer survivors will need prompt intervention for the late effects of cancer. We provide empiric evidence that depression is a significant health concern among breast cancer survivors even well beyond the cancer treatment phase. The study highlights the need for healthcare providers to continue to monitor women with breast cancer for depression and to provide timely and appropriate posttreatment psychosocial care to cancer survivors.

\section{Acknowledgments}

This work was supported by grants from the National Cancer Institute (CA109043) and Pfizer, Inc.

\section{Disclosure Statement}

No competing financial interests exist.

\section{References}

1. Jemal A, Siegel R, Xu J, Ward E. Cancer statistics, 2010. CA Cancer J Clin 2010;60:277-300.

2. www.cancer.org/. 2011.

3. Reddick BK, Nanda JP, Campbell L, Ryman DG, GastonJohansson F. Examining the influence of coping with pain on depression, anxiety, and fatigue among women with breast cancer. J Psychosoc Oncol 2005;23:137-157.

4. Spiegel D, Giese-Davis J. Depression and cancer: Mechanisms and disease progression. Biol Psychiatry 2003;54:269282.

5. Kreitler S, Chaitchik S, Rapoport Y, Algor R. Psychosocial effects of level of information and severity of disease on head-and-neck cancer patients. J Cancer Educ 1995;10:144154.

6. Kroenke K, Theobald D, Wu J, Loza JK, Carpenter JS, Tu W. The association of depression and pain with health-related quality of life, disability, and health care use in cancer patients. J Pain Symptom Manage 2010;40:327-341.

7. Kroenke K, Theobald D, Wu J, Loza JK, Carpenter JS, Tu W. The association of depression and pain with health-related quality of life, disability, and health care use in cancer patients. J Pain Symptom Manage 2010;40:327-341.

8. Lynch ME. The assessment and prevalence of affective disorders in advanced cancer. J Palliat Care 1995;11:10-18.

9. Jeon HJ, Shim EJ, Shin YW, et al. Discrepancies in performance status scores as determined by cancer patients and oncologists: Are they influenced by depression? Gen Hosp Psychiatry 2007;29:555-561.

10. Walsh D, Donnelly S, Rybicki L. The symptoms of advanced cancer: Relationship to age, gender, and performance status in 1,000 patients. Support Care Cancer 2000;8:175-179.

11. Christensen $S$, Zachariae $R$, Jensen $A B$, et al. Prevalence and risk of depressive symptoms 3-4 months postsurgery in a nationwide cohort study of Danish women treated for early stage breast cancer. Breast Cancer Res Treat 2009;113:339355.

12. Giese-Davis J, Collie K, Rancourt KM, Neri E, Kraemer HC, Spiegel D. Decrease in depression symptoms is associated with longer survival in patients with metastatic breast cancer: A secondary analysis. J Clin Oncol 2011;29:413-420.

13. Caplette-Gingras A, Savard J. Depression in women with metastatic breast cancer: A review of the literature. Palliat Support Care 2008;6:377-387.

14. Casso D, Buist DS, Taplin S. Quality of life of 5-10 year breast cancer survivors diagnosed between age 40 and 49 . Health Qual Life Outcomes 2004;2:25.

15. Reich M, Lesur A, Perdrizet-Chevallier C. Depression, quality of life and breast cancer: A review of the literature. Breast Cancer Res Treat 2008;110:9-17.

16. Yen JY, Ko CH, Yen CF, et al. Quality of life, depression, and stress in breast cancer women outpatients receiving active therapy in Taiwan. Psychiatry Clin Neurosci 2006;60:147-153.

17. Burgess C, Cornelius V, Love S, Graham J, Richards M, Ramirez A. Depression and anxiety in women with early breast cancer: Five year observational cohort study. BMJ 2005;330:702.

18. Den Oudsten BL, Van Heck GL, Van der Steeg AF, Roukema JA, De Vries J. Predictors of depressive symptoms 12 months after surgical treatment of early-stage breast cancer. Psy- 
chooncology 2009 Nov;18(11): 1230-1237. PubMed PMID: 19142843.

19. Vahdaninia M, Omidvari S, Montazeri A. What do predict anxiety and depression in breast cancer patients? A follow-up study. Soc Psychiatry Psychiatr Epidemiol 2010;45:355-361.

20. Kim SH, Son BH, Hwang SY, et al. Fatigue and depression in disease-free breast cancer survivors: Prevalence, correlates, and association with quality of life. J Pain Symptom Manage 2008;35:644-655.

21. Reyes-Gibby CC, Morrow PK, Buzdar A, Shete S. Chemotherapy-induced peripheral neuropathy as a predictor of neuropathic pain in breast cancer patients previously treated with paclitaxel. J Pain 2009;10:1146-1150.

22. Reyes-Gibby C, Morrow PK, Bennett MI, Jensen MP, Shete S. Neuropathic pain in breast cancer survivors: Using the ID pain as a screening tool. J Pain Symptom Manage 2010;39:882-889.

23. Kroenke K, Strine TW, Spitzer RL, Williams JB, Berry JT, Mokdad AH. The PHQ-8 as a measure of current depression in the general population. J Affect Disord 2009;114:163-173.

24. Corson K, Gerrity MS, Dobscha SK. Screening for depression and suicidality in a VA primary care setting: 2 items are better than 1 item. Am J Managed Care 2004;10:839-845.

25. Kroenke K, Spitzer RL, Williams JB. The PHQ-9: Validity of a brief depression severity measure. J Gen Intern Med 2001;16:606-613.

26. Fayers PM, Aaronson NK BKCDGM. on behalf of of the EORTC Quality of Life Study Group (1999). EORTC QLQ-30 reference Values. Brussels, 1999. http://groups.eortc.be/ gol/downloads/reference_values_manual2008.pdf

27. Reyes-Gibby CC, Aday L, Cleeland C. Impact of pain on self-rated health in the community-dwelling older adults. Pain 2002;95:75-82.

28. Reyes-Gibby CC, Aday LA, Anderson KO, Mendoza TR, Cleeland CS. Pain, depression, and fatigue in communitydwelling adults with and without a history of cancer. J Pain Symptom Manage 2006;32:118-128.

29. Bendel RB, Afifi AA. Comparison of stopping rules in forward regression, J Am Stat Assoc 1977;72:46-53.

30. McDaniel JS, Musselman DL, Porter MR, Reed DA, Nemeroff CB. Depression in patients with cancer. Diagnosis, biology, and treatment. Arch Gen Psychiatry 1995;52:89-99.

31. Miovic M, Block S. Psychiatric disorders in advanced cancer. Cancer 2007;110:1665-1676.

32. Andritsch E, Dietmaier G, Hofmann G, Zloklikovits S, Samonigg $\mathrm{H}$. Global quality of life and its potential predictors in breast cancer patients: An exploratory study. Support Care Cancer 2007;15:21-30.

33. Caplette-Gingras A, Savard J. Depression in women with metastatic breast cancer: A review of the literature. Palliative Support Care 2008;6:377-387.

34. Clemmens DA, Knafl K, Lev EL, McCorkle R. Cervical cancer: Patterns of long-term survival. Oncol Nurs Forum 2008;35:897-903.

35. Reich M, Lesur A, Perdrizet-Chevallier C. Depression, quality of life and breast cancer: A review of the literature. Breast Cancer Res Treat 2008;110:9-17.

36. Montazeri A. Health-related quality of life in breast cancer patients: A bibliographic review of the literature from 1974 to 2007. J Exp Clin Cancer Res 2008;27:32.

37. Groenvold M, Fayers PM, Petersen MA, Sprangers MA, Aaronson NK, Mouridsen HT. Breast cancer patients on adjuvant chemotherapy report a wide range of problems not identified by health-care staff. Breast Cancer Res Treat 2007;103:185-195.
38. Thekkumpurath $\mathrm{P}$, Walker J, Butcher I, et al. Screening for major depression in cancer outpatients: The diagnostic accuracy of the 9-item Patient Health Questionnaire. Cancer 2011;117:218-227.

39. Pomeroy IM, Clark CR, Philp I. The effectiveness of very short scales for depression screening in elderly medical patients. Int J Geriatr Psychiatry 2001;16:321-326.

40. Chochinov HM, Wilson KG, Enns M, Lander S. "Are you depressed?" Screening for depression in the terminally ill. Am J Psychiatry 1997;154:674-676.

41. Fisch M. Treatment of depression in cancer. J Natl Cancer Inst Monogr 2004;105-111.

42. Holland JC, Bultz BD. The NCCN guideline for distress management: A case for making distress the sixth vital sign. J Natl Compr Cancer Netw 2007;5:3-7.

43. Roberts AA. The labor market consequences of family illness. J Ment Health Policy Econ 1999;2:183-195.

44. Mols F, Vingerhoets AJ, Coebergh JW, van de Poll-Franse LV. Quality of life among long-term breast cancer survivors: A systematic review. Eur J Cancer 2005;41:2613-2619.

45. Lueboonthavatchi P. Prevalence and psychosocial factors of anxiety and depression in breast cancer patients. J Med Assoc Thai 2007;90:2164-2174.

46. Bennett B, Goldstein D, Lloyd A, Davenport T, Hickie I. Fatigue and psychological distress-Exploring the relationship in women treated for breast cancer. Eur J Cancer 2004;40:1689-1695.

47. Schag CA, Ganz PA, Polinsky ML, Fred C, Hirji K, Petersen L. Characteristics of women at risk for psychosocial distress in the year after breast cancer. J Clin Oncol 1993;11:783793.

48. Politi MC, Enright TM, Weihs KL. The effects of age and emotional acceptance on distress among breast cancer patients. Support Care Cancer 2007;15:73-79.

49. Kornblith AB, Powell M, Regan MM, et al. Long-term psychosocial adjustment of older vs. younger survivors of breast and endometrial cancer. Psychooncology 2007;16:895903.

50. Meneses K, McNees P, Azuero A, Jukkala A. Evaluation of the Fertility and Cancer Project (FCP) among young breast cancer survivors. Psychooncology 2010;19:1112-1115.

51. Ganz PA. Psychological and social aspects of breast cancer. Oncology (Williston Park) 2008;22:642-646.

52. Dickens C, McGowan L, Clark-Carter D, Creed F. Depression in rheumatoid arthritis: A systematic review of the literature with meta-analysis. Psychosom Med 2002;64:52-60.

53. Wolfe F, Michaud K. Predicting depression in rheumatoid arthritis: The signal importance of pain extent and fatigue, and comorbidity. Arthritis Rheum 2009;61:667-673.

54. Mehnert A, Koch U. Psychological comorbidity and healthrelated quality of life and its association with awareness, utilization, and need for psychosocial support in a cancer register-based sample of long-term breast cancer survivors. J Psychosom Res 2008;64:383-391.

55. Schroevers M, Ranchor AV, Sanderman R. Adjustment to cancer in the 8 years following diagnosis: A longitudinal study comparing cancer survivors with healthy individuals. Soc Sci Med 2006;63:598-610.

56. Goodwin JS, Zhang DD, Ostir GV. Effect of depression on diagnosis, treatment, and survival of older women with breast cancer. J Am Geriatr Soc 2004;52:106-111.

57. Hjerl K, Andersen EW, Keiding N, Mouridsen HT, Mortensen PB, Jorgensen T. Depression as a prognostic factor for breast cancer mortality. Psychosomatics 2003;44:24-30. 
58. Diez-Quevedo C, Rangil T, Sanchez-Planell L, Kroenke K, Spitzer RL. Validation and utility of the Patient Health Questionnaire in diagnosing mental disorders in 1003 general hospital Spanish inpatients. Psychosom Med 2001;63:679-686.

59. Spitzer RL, Kroenke K, Williams JB. Validation and utility of a self-report version of PRIME-MD: The PHQ primary care study. Primary care evaluation of mental disorders. Patient Health Questionnaire. JAMA 1999;282:1737-1744.
Address correspondence to:

Cielito C. Reyes-Gibby, DrPH Department of Epidemiology, Unit \#1340 The University of Texas M.D. Anderson Cancer Center 1155 Pressler Drive Houston, TX 77030

E-mail: creyes@mdanderson.org 